\title{
IMIGRAÇÃO: IDENTIDADE E TERRITÓRIO NUMA CONCEPÇÃO DE PÓS-MODERNIDADE
}

\author{
Msc. Marinaldo de Almeida Cunha ${ }^{1}$
}

Dr $^{\mathrm{a}}$. Leda Maria de Oliveira Rodrigues ${ }^{2}$

\section{RESUMO}

De modo geral, podia-se dizer que estudar imigração consistia em lidar com a imersão de uma determinada cultura numa outra, configurando uma situação com muitos desafios, tanto para o imigrante quanto para a comunidade receptora. No entanto, a atual configuração da sociedade mostra que essa concepção está mudada, pois tendo em vista um mundo no qual as identidades estão particularizadas, atravessadas pelas informações globais, e onde as distâncias estão cada vez menores, a identificação com a cultura nacional e, principalmente com o território, não está mais tão marcada nos indivíduos como nos séculos passados, inclusive naqueles que fazem parte dos fluxos migratórios. Neste prisma, a identidade não está mais determinada nos indivíduos como uma entidade rígida que representa um conjunto homogêneo de pessoas; atualmente, está marcada pela transitoriedade, isto é, pela instabilidade da rápida evolução que os meios de comunicação e mídias sociais imprimem à sociedade atual, na qual tudo está mais evidente, mais rápido, mais intenso e, sobretudo, individualizado. Analisando o caso de um refugiado sírio, este artigo estimula a reflexão sobre a identidade do migrante como uma ruptura do sentimento nacional e territorial, tornando-se individualizado em suas experiências individuais, inserida numa perspectiva de pós-modernidade.

Palavras-chave: Imigração, Pós-modernidade, Identidade. Multiterritorialidade.

\footnotetext{
${ }^{1}$ Doutorando no Programa de Estudos Pós-Graduados em Educação: História, Política, Sociedade na Pontifícia Universidade Católica de São Paulo, como bolsista do CNPq, membro do Grupo de Pesquisa Movimentos Migratórios e Educação vinculado ao mesmo programa.

${ }^{2}$ Professora Titular de Fundamentos da Educação na Pontifícia Universidade Católica de São Paulo, onde é docente no Programa de Estudos Pós-Graduados em Educação: História, Política, Sociedade, pesquisadora líder no Grupo de Pesquisa Movimentos Migratórios e Educação vinculado ao mesmo programa.
} 
Immigration: identity and territory in a postmodern conception

\begin{abstract}
In general, it could be said that studying immigration consisted in dealing with the immersion of one culture into another, setting up a situation with many challenges for both the immigrant and the receiving community. However, the current configuration of society shows that this conception has changed. It occurred due to the social transformations in the world in which identities are particularized, crossed by global information. Distances are getting smaller, identification with national culture and, especially with the territory, is no longer so important for the individuals as in past centuries, including those wo are part of migratory flows. In this light, identity is no longer determined in individuals as a rigid entity that represents a homogeneous set of people, so it is marked by transience, that is, by the instability of the rapid evolution that the media and social media imprint on today's society. Nowadays everything is more evident, faster, and more intense and, above all, individualized. Analysing the case of a Syrian refugee, this article encourages the reflection of the migrant's identity as a rupture of national and territorial feeling, becoming individualized in individual experiences, inserted in a postmodern perspective.
\end{abstract}

Key Words: Immigration. Postmodernity. Identity. Multiterritoriality.

\title{
Introdução
}

Os últimos anos têm sido marcados por grandes fluxos migratórios em todo o mundo. Dentre eles, os mais conhecidos são a travessia do Mediterrâneo por africanos que tentam entrar na Europa, os refugiados no Oriente-Médio, e latino-americanos que tentam entrar nos Estados Unidos. No Brasil, esse novo cenário da imigração tornou-se evidente em 2010 com a chegada de haitianos, que fugiam de um país devastado por duas catástrofes seguidas, um furacão em 2008 e um terremoto em 2010, que juntos mataram mais de 700 mil haitianos. Anos depois o território brasileiro também passou a receber refugiados sírios, em razão da guerra na Síria e outros conflitos armados, consequência da Primavera Árabe. (RODRIGUES, 2016; BOGUS; FABIANO, 2015). 
Mais recentemente, a crise política, econômica e social na Venezuela gerou um fluxo intenso de emigração do país, do qual o Brasil recebe uma parte através das fronteiras da região norte. (FGV, 2018).

Nota-se que a entrada de milhares de imigrantes na América do Sul evidencia a ocorrência de novos fluxos, distintos daqueles tradicionalmente conhecidos que, em regra, se tratavam de migrantes de países pobres indo para países mais ricos.

Nesse quadro, o Brasil apresenta números expressivos que confirmam a grande procura por migrantes oriundos de países do eixo sul do globo, principalmente nos últimos dez anos, marcados pela grande exposição midiática deste cenário, veiculando notícias e matérias acerca do tema das migrações, a exemplo de histórias de vida, cultura, identidades ou, mesmo, narrativas sobre caminhos percorridos por migrantes, desde sua saída até estabelecimento em novo território.

É justamente sobre essas últimas perspectivas que este artigo se debruça fazendo análise de algumas questões referentes à identidade e ao território, trazendo o caso de um refugiado sírio que saiu de seu país e já percorreu outros dois antes de chegar ao Brasil e se instalar com sua família. Os principais interlocutores serão Hall (2015) e Bauman (2001; 2005) no campo da identidade e Haesbaert (2005) nas discussões sobre territórios e Sayad (1998; 2001) na temática das migrações.

$\mathrm{Na}$ seção a seguir, serão discutidas algumas ideias sobre identidade que foram levantadas com base na narrativa do sujeito investigado, aqui chamado de Mohamed.

\section{O caso de Mohamed}

Mohamed é um jovem sírio de trinta e dois anos, casado e pai de dois meninos, um de cinco anos e outro recém-nascido. Formado em Computação, trabalha com engenharia de softwares e está no Brasil desde o final de 2015.

Em 2011, Mohamed e sua esposa saíram da Síria, que estava em conflito, para viver como refugiados na Jordânia, onde conseguiram ficar por um ano na capital Amã. Nesse tempo, tiveram seu primeiro filho. Da Jordânia, a família foi para a Turquia, onde viveu por três anos e meio, mas a vida estava difícil pelo fato de esse país estar recebendo muitos refugiados sírios e, consequentemente, os recursos estarem cada vez mais escassos.

A decisão de vir para o Brasil, além das difíceis condições de vida em Istambul, foi tomada depois de pesquisar por países que estavam aceitando o refúgio de sírios; a resposta brasileira foi a primeira positiva. Depois dessa resposta, Mohamed passou a pesquisar sobre 
cidades brasileiras que oferecessem boa qualidade de vida para sua família, e entre Curitiba, São Paulo e Florianópolis, ele decidiu que a primeira seria seu destino para os próximos anos.

Mohamed e sua família já estão no Brasil há pouco mais de dois anos e bem adaptados ao país, sobretudo às regras de convivência que limitam suas práticas religiosas e os costumes de casa, como o fato de o condomínio ter proibido deixar os calçados da família e de convidados do lado de fora do apartamento, na área comum do prédio. Além disso, ele fala que já se aceita como um estrangeiro na condição de religioso, que vê limitação na prática de suas orações diárias, pelo fato de existirem poucas mesquitas na cidade, o que o leva a sempre vigiar seus horários para que não perca a oração, pois "no meu país ou em outro país mulçumano a gente caminha apenas 15 minutos até encontrar uma mesquita, e aqui elas são mais longe, aí eu faço minha oração ou na universidade ou em casa, porque não dá para fazer na rua, precisa de um lugar limpo".

O caso de Mohamed, que precisa se adequar a realidades distintas daquela de sua origem, mostra o quão fluido ele precisa ser para se adaptar noutros lugares na condição de refugiado. Serão observados três aspectos desse caso particular: o migrante e a "dupla ausência"; a identidade e o indivíduo líquido e a multiterritorialidade.

\section{Mohamed, o estrangeiro}

Quando perguntado sobre como se sentia no Brasil, ele falou que as pessoas sabem que ele é um estrangeiro e é assim que ele se sente, principalmente em duas ocasiões. O primeiro momento que ele relatou é quando está fazendo oração na universidade, momento em que ele precisa ir para uma sala vazia e silenciosa:

Tem uma coisa na nossa religião que é difícil praticar aqui no Brasil. Porque mulçumano tem que rezar cinco vezes no dia, em horários específicos. O problema é que se você está fora de casa é bem difícil praticar essa oração, porque é obrigatório, não é coisa que você pode deixar para outra hora. Entre essa hora e essa hora tem a oração, então tem que fazer isso. É difícil praticar isso fora de casa. No nosso país ou nos países mulçumanos tem muitas mesquitas, então é fácil entrar para rezar, mas no Brasil não tem e qualquer país que não seja mulçumano não tem, aí tem que acostumar. Precisa de um lugar limpo, é difícil, vou na universidade para o curso de português, aí eu escolho uma sala vazia 
para fazer, mas na rua é difícil. No meu país se encontra fácil uma mesquita, é igual igreja aqui, no máximo caminha quinze minutos e encontra uma. Na universidade tem pessoas que olham e não sabem o que eu estou fazendo porque não conhecem. Elas não falam, mas eu sinto que elas acham estranho. E eu me sinto como um estrangeiro. (Mohamed, em entrevista, 2018).

Em vários momentos em seu discurso, especialmente ligados à religião, Mohamed se mostra incomodado por ser o fator mais impactante da imigração e sempre menciona o "seu país” em comparação. Por ser muito disciplinado na religião, ele adaptou toda a rotina para que os horários de oração sejam a ou em casa ou na universidade, porque "tem que fazer".

Outro momento mencionado por Mohamed em que se sente um estrangeiro é quando está na rua com sua esposa - que logo são reconhecidos por ela usar o hijab": "sempre que caminhamos na rua as pessoas sabem que somos árabes, por conta que minha esposa usa o hijab, e isso é expressão da nossa cultura".

Mas, apesar de se sentir um estrangeiro por conta da reação das pessoas, ele não sente que elas têm racismo ou preconceito, que apenas esboçam uma reação por ser uma cena incomum de se ver no dia a dia no Brasil. No entanto, ele relatou que acha difícil expressar a cultura deles aqui no país porque são costumes diferentes, então a forma como podem se expressar culturalmente, além da religião, é por meio da comida e no modo de vestir.

Semanalmente eles também têm encontros com uma pequena comunidade mulçumana numa mesquita, cerca de cinquenta pessoas. Lá eles podem falar a língua árabe e praticar suas orações e costumes sem nenhuma interferência ou censura.

Nota-se que existe um sentimento de liberdade em poder conviver e se expressar, e esse quadro atual, vale a pena relembrar, é muito diferente do que acontecia no nacionalismo e "abrasileiramento" da década de 1930 no Brasil, quando os imigrantes eram proibidos de expressar sua cultura e sua língua, em nome de uma promoção da cultura brasileira e da língua portuguesa. (SEIFFERTH, 2005).

Esses e outros fatores que fazem parte da identidade de Mohamed serão analisados de acordo com a perspectiva de Hall (2015) e Bauman (2001; 2005), os quais trazem uma

\footnotetext{
${ }^{3}$ Hijab ou Hijabe é o nome das vestimentas tradicionais da cultura islâmica utilizadas pelas mulheres, que visam à privacidade feminina.
} 
perspectiva individualizada das questões identitárias no novo contexto global, por vezes denominado pós-modernismo.

\section{Imigração e Identidade: um indivíduo pós-moderno?}

Bauman (2005) põe em xeque a questão da identidade com base no contexto de múltiplas possibilidades que se vivem hoje, no qual fica cada vez mais defasado o pensamento de segurança, estabilidade.

O anseio por identidade vem do desejo de segurança, ele próprio um sentimento ambíguo. Embora possa parecer estimulante no curto prazo, cheio de promessas e premonições vagas de uma experiência ainda não vivenciada, flutuar sem apoio num espaço pouco definido, num lugar teimosamente, perturbadoramente, "nem-um-nem-outro", torna-se a longo prazo uma condição enervante e produtora de ansiedade. Por outro lado, uma posição fixa dentro de uma infinidade de possibilidades também não é uma perspectiva atraente. Em nossa época líquidomoderna, em que o indivíduo livremente flutuante, desimpedido, é o herói popular, "estar fixo" - ser "identificado" de modo inflexível e sem alternativa - é algo cada vez mais mal visto. (BAUMAN, 2005, p. 35).

O pensamento acima destaca que o indivíduo global não está satisfeito com aquela ideia de estabilidade vivida pelos seus antepassados, especialmente no que diz respeito à identidade nacional homogênea, rígida, dependente do território. Isso marca a superação ou rompimento com o sentimento de que o homem cria raízes conforme a idade avança. Hoje o homem se permite ser mais do que simplesmente um status ou uma posição social, ele quer ser multitarefa, inclusive nas relações de trabalho, onde a identidade profissional está cada vez mais fluida.

O caso de Mohamed é um exemplo dessa nova configuração das relações de trabalho, pois ele vive no Brasil, trabalha on-line como autônomo desenvolvendo softwares para empresas em Dubai e recebe seus vencimentos em dólares americanos.

Da mesma forma que as relações de trabalho não são mais as mesmas, não existindo mais a antiga preocupação com a solidez num determinado status social, as relações humanas (familiares e além da família) também estão se transformando. Isso também se aplica ao lugar de instalação ou estabelecimento, que não é mais tratado como o porto seguro, no qual se pensa 
construir o ninho familiar. Não há mais grande interesse pela definição, estabilidade. Assim como o indivíduo não se prende a uma raiz, ele também não deseja ser identificado como representante de tal cultura, ele é uma identidade única, sem algo que o prenda ou defina (nem antes, nem agora, nem depois). A respeito disso, Bauman escreve que:

A abundância dos compromissos oferecidos, mas principalmente a fragilidade de cada um deles, não inspira confiança em investimentos de longo prazo no nível das relações pessoais ou íntimas. Tampouco inspira confiança no local de trabalho, onde o status social costumava ser definido, onde a vida continua a ser ganha e os direitos de dignidade e respeito social continuam a ser obtidos ou perdidos. Num artigo recente, Richard Sennett assinala que "um local de trabalho flexível provavelmente não seria o lugar onde alguém desejaria construir um ninho". Ao mesmo tempo, com a duração média do contrato de trabalho ("projeto") nas mais avançadas empresas de alta tecnologia em lugares como o admirado Vale do Silício girando em torno de oito meses, a solidariedade de grupo que costumava fornecer o campo para o desenvolvimento da democracia não tem tempo para fincar raízes e amadurecer. Há poucos motivos para se esperar que a lealdade de uma pessoa ao grupo ou organização seja retribuída. É insensato (“irracional") oferecer tal lealdade a crédito quando é improvável que seja recompensada. (BAUMAN, 2005, p. 36).

O texto revela que não há interesse pelo reconhecimento, pois as relações no novo contexto global são voláteis ao ponto de não permitir a criação de raízes. O mesmo sentimento aplica-se à vida pessoal, então o indivíduo deixa de se prender a lugares, pessoas, assim como está desprendido de status social. Dessa forma, tanto faz estar aqui, como ali. E essa é uma das principais características quando se trata do indivíduo migrante, o qual não sente grandes impactos estando em lugares diferentes.

Se tornar dinâmico é mais do que uma aventura, é uma obrigação na atualidade, por dois motivos: o primeiro se refere à alta velocidade das informações e das relações; e o segundo motivo, que tem uma relação direta com o primeiro, é a curta duração dos projetos nos quais o indivíduo se envolve. 
Estar em movimento, antes um privilégio e uma conquista, não é mais, portanto, uma questão de escolha: agora se tornou um "must". Manterse em alta velocidade, antes uma divertida aventura, transformou-se em uma tarefa exaustiva. (BAUMAN, 2005, p. 37-38).

O autor deixa claro o quanto as relações estão mais dinâmicas do que já foram, afirmando que para o indivíduo não há outra escolha se não se mover conforme as oportunidades, isto é, na velocidade com que o mundo líquido flui. Da mesma forma que há fluidez e velocidade, as relações acabaram se tornando de curta duração, exigindo mudança constante.

Isso é válido para as diversas relações, inclusive de trabalho.

Pierre Bourdieu e Richard Sennett explicaram por que o esfacelamento de cenários e rotinas anteriormente estáveis e a fragilidade recémrevelada até mesmo por empresas grandes e aparentemente sólidas não favorecem uma postura de união e solidariedade, além de evitar que problemas e ansiedades individuais se intensifiquem no conflito de classes. Como nos mostram Boltanski e Chiapello, os empregados se viram numa cité par projets, onde as perspectivas de empregos são confinadas a um único projeto atualmente em andamento. E entre as pessoas que vivem de um projeto para outro, pessoas cujos processos de vida são desmembrados numa sucessão de projetos de curta duração, não há tempo para que descontentamentos difusos se reduzam à busca por um mundo melhor... Tais pessoas prefeririam um hoje diferente para cada um a pensarem seriamente num futuro melhor para todos. Em meio ao esforço diário apenas para se manter à tona, não há espaço nem tempo para uma visão da "boa sociedade". (BAUMAN, 2005, p. 41).

Essa fala de Bauman refere-se também à forte individualização que marca este mundo fluido, o qual, além de representar o sentimento de não pertencimento a determinado grupo, pois o indivíduo trata cada relação como uma provisoriedade, fortalece o distanciamento de um 
projeto comum, isto é, de comunidade, de classe. Este sentimento ou movimento faz com que a ideia de estabilidade fique fragilizada ou deixe de existir.

Com base nesse ponto de vista, reforça-se que a noção de identidade não é mais a mesma, pois não cabe, pelo menos no contexto global (líquido), a identificação com um grupo, uma nação etc. O homem está cada vez mais resumido a si mesmo e a seus sucessivos projetos de vida de curta duração.

Este conceito é mais bem ilustrado quando se observa a figura do migrante, pois fica patente a questão do desprendimento, primeiro à ideia de território, depois de nação, e mais adiante de identidade cultural.

Na próxima seção, será discutida a questão da transitoriedade, mais precisamente da identidade e do território nesse contexto de mundo líquido, global ou pós-moderno, com base no relato do entrevistado sírio Mohamed, que vive em Curitiba.

\section{O eu transitório e multiterritorial: a fluidez do indivíduo pós-moderno}

A questão central que será discutida nesta seção é o conceito de indivíduo inserido num mundo no qual as relações sociais e de trabalho estão se reconfigurando. Foi adotada, então, a concepção de pós-modernidade, talvez de forma ousada, tendo em vista que essa nomenclatura não é consenso ou aceita de forma unânime na academia.

Para embasar o pensamento desenvolvido aqui, será utilizada a percepção de Hall (2015) acerca da identidade cultural na pós-modernidade, além das discussões sobre identidade de Bauman (2005), já apresentadas anteriormente. Esses dois pesquisadores têm uma proximidade no entendimento da nova configuração do indivíduo e da identidade no contexto global no século XXI.

Em essência, o argumento é o seguinte: as velhas identidades, que por tanto tempo estabilizaram o mundo social, estão em declínio, fazendo surgir novas identidades e fragmentando o indivíduo moderno, até aqui visto como um sujeito unificado. A assim chamada "crise de identidade" é vista como parte de um processo mais amplo de mudança, que está deslocando as estruturas e processos centrais das sociedades modernas e abalando os quadros de referência que davam aos indivíduos uma ancoragem estável no mundo social. (HALL, 2015, p. 9). 
Esse pensamento incita a discussão de que há uma perda da "ancoragem" do homem em relação às estruturas das sociedades modernas, que transferiam um sentimento de segurança e estabilidade, ao mesmo tempo em que imprimiam nos indivíduos o seu status. O indivíduo da modernidade passa a perder espaço para essa nova configuração de identidade, fazendo nascer o indivíduo "pós-moderno" ou a noção da identidade no contexto de pós-modernidade no qual as relações sociais estão pautadas na liquidez dos processos.

Com quem eu posso me identificar? Em qual lugar eu posso viver? Essas são perguntas que o eu pós-moderno pode responder de forma ambígua. Ao mesmo tempo em que eu me identifico com o mundo inteiro, eu não me sinto identificado como nada disso que está posto. $\mathrm{E}$, dessa maneira, eu posso viver em qualquer lugar do mundo, pois não me sinto pertencente a lugar nenhum.

A respeito disso, quando discutia sobre a relação entre imigração e desterritorialização, Haesbaert (2005) já mencionava o indivíduo como portador de uma "multiterritorialidade". Segundo o autor:

O migrante, esta figura genérica definida sobretudo pela sua mobilidade, é na verdade um sujeito múltiplo, ou melhor, a migração é um processo multifacetado. Na problemática aqui trabalhada, mais ainda, é necessário sempre qualificar o migrante ou a migração de que estamos falando. Não há, assim, uma desterritorialização genérica ligada às migrações, pois, ao contrário do que pensam muitos autores, a simples mobilidade física não é suficiente para defini-la. Assim, como a fixidez em um determinado espaço não é suficiente para (re)territorializar, o movimento não é suficiente para desterritorializar. (HAESBAERT, 2005, p. 43).

Com isso, Haesbaert (2005) combate a tão difundida ideia de que o imigrante é um ser que perdeu um território e ganhou outro, pois, na verdade, o pensamento desse autor mostra que o migrante pode carregar consigo todos os territórios nos quais já viveu e vive, como um ser múltiplo, pois o significado de território não está apenas na terra por si só e, sim, nas experiências e na troca vivenciada, que constrói dentro de si a noção de território. Da mesma forma, pelo mesmo motivo, não se desterritorializa quando se desloca, mas leva consigo a experiência espacial vivida e construída ali. 
Desse modo, entende-se que essa noção de pertencimento não está mais ligada a nenhum território físico, o indivíduo carrega em si, na sua transitoriedade, os seus territórios, que são, segundo as reflexões do autor, uma experiência do espaço e que, estando no indivíduo, não se perde no simples movimento, pelo contrário, se torna múltiplo à medida que o indivíduo se desloca, reterritorializando-se.

Mohamed, quando fala em "seu país", está trazendo consigo as experiências espaciais vividas naquele território, o qual não é e não será o mesmo num possível retorno. E ele demostrou essa consciência de que não reconhecerá mais o seu país ao retornar, quando falou que a guerra está destruindo tudo no lugar onde ele vivia antes de emigrar e nada será mais como antes.

Esse pensamento assemelha-se muito com as reflexões de Sayad em dois aspectos: quando fala que no seu retorno o país não será o mesmo e a própria ideia de que irá retornar, que a imigração é provisória. Sayad (1998) reflete sobre o fato ou ideia do caráter provisório que está intimamente ligado ao conceito de imigrante:

Uma das características fundamentais do fenômeno da imigração é que, fora algumas situações excepcionais, ele contribui para dissimular a si mesmo sua própria verdade. Por não conseguir sempre pôr em conformidade o direito e o fato, a imigração condena-se a engendrar uma situação que parece destiná-la a uma dupla contradição: não se sabe mais se se trata de um estado provisório que se gosta de prolongar indefinidamente ou, ao contrário, se se trata de um estado mais duradouro mas que se gosta de viver com um intenso sentimento de provisoriedade. Oscilando, segundo as circunstâncias, entre o estado provisório que a define de direito e a situação duradoura que a caracteriza de fato, a situação do imigrante se presta, não sem alguma ambiguidade, a uma dupla interpretação: ora, como que para não confessar a si mesmo a forma quase definitiva que com frequência cada vez maior a imigração reveste, apenas se leva em conta na qualidade de imigrante o seu caráter eminentemente provisório (de direito); ora, ao contrário, como se fosse preciso desmentir a definição oficial do estado de imigrante como estado provisório, insiste-se com razão na tendência atual que os imigrantes possuem de se "instalar" de forma cada vez mais duradoura em sua condição de imigrantes. (SAYAD, 1998, p. 45). 
Assim como o autor nos coloca, Mohamed carrega em seu discurso que está vivendo com sua família um estado provisório, que os mantém no estado de migrante. Complementarmente a isso, ele mantém a esperança de um retorno, o que Sayad (2010) também aponta como uma das "mentiras" ou "fantasias" mais comuns no discurso do migrante, o mito do retorno. Sobre essa condição, Dadalto (2011, p. 30) afirma que "somente quando o imigrante consegue dissolver de si próprio a inscrição do retorno à terra natal ele deixa de ser o estrangeiro".

De fato, enquanto Mohamed carrega em si a esperança e fantasia de que voltará para "seu país", a distância entre ele e o Brasil será grande, e ele sempre se sentirá como um estrangeiro, em sua convivência, em suas práticas. Mas o que ele sente ao final das contas?

Esse sentimento de ausência tanto como emigrado que deixou o "seu país" quanto como imigrante que se refugia no Brasil, configura o que Sayad (2010) denomina de doble ausencia. Esse conceito, grosso modo, diz respeito ao sentimento do migrante em relação à terra natal, à qual ele não se sente mais pertencente, pois não faz mais parte do que lá existe hoje, e ao mesmo tempo o sentimento de não pertencimento à terra receptora.

Esses dois conceitos, tanto o de ausência do Sayad, quanto o de multiterritorialismo de Haesbaert, são pontos fundamentais para sustentar o caminho que aqui se trilha, na pretensão de lançar a ideia de uma configuração pós-modernista de indivíduo, o qual se pretende líquido no mundo, transitório na própria existência e com uma nova noção espacial.

Num mundo que cada vez se apresenta fluido e sem fronteiras, onde a informação flui numa velocidade jamais contada na história, é razoável que também se pense num homem com essa quebra de paradigmas, que rompe com as estruturas tradicionais da sociedade moderna e que aponte para um futuro ainda mais sem predefinições nem barreiras sociais, culturais ou linguísticas. Ainda longe de ser um consenso ou mesmo uma ideia aceitável, o pensamento sobre um discurso de pós-modernismo mostra-se, portanto, cada vez mais presente, configurando-se como pauta inadiável para que se possa pensar a sociedade do século XXI.

\section{Referências bibliográficas}

BAUMAN, Zigmunt. Modernidade líquida. Rio de Janeiro: Zahar, 2001.

BAUMAN, Zigmunt. Identidade. Rio de Janeiro: Zahar, 2005. 
BOGUS, L. M. M.; FABIANO, M. L. A. O Brasil como destino das migrações internacionais recentes: novas relações, possibilidades e desafios. Ponto e Vírgula. São Paulo: PUC- SP, no 18, p. 126-145, 2015.

DALDATO, Maria Cristina. Trajetórias migrantes: ambivalência na interação 'nós' e os ‘outros'. In: Dimensões, vol. 26. Vitória: UFES, 2011.

FGV/ DAPP. Desafio Migratório em Roraima: repensando a política e gestão da imigração no Brasil. Rio de Janeiro: FGV/DAPP, 2018.

HAESBAERT, Rogério. Migração e desterritorialização. In: PÓVOA NETO, H.; FERREIRA, A. P. (Orgs.). Cruzando fronteiras disciplinares: um panorama dos estudos migratórios. Rio de Janeiro: Revan, 2005. p. 35-46.

HAESBAERT, Rogério. Da desterritorialização à multiterritorialidade. Anais do IX Encontro Nacional da ANPUR. v. 3. Rio de Janeiro, 2001. p. 1769-1777.

HALL, Stuart. A identidade cultural na pós-modernidade. Rio de Janeiro: Lamparina, 2015.

RODRIGUES, L. M. O. Escola-território, desterritorialização e análises educacionais. Ponto e Vírgula, São Paulo: PUCSP, n. 20, segundo semestre 2016, p. 56-82, 2016.

SAYAD, A. La Doble Ausencia: de las ilusiones del emigrado a los padecimientos del inmigrado. Prefácio de Pierre Bourdieu. Coleção Autores, Textos y Temas. Ciencias Sociales, $\mathrm{n}^{\circ}$ 77. Barcelona: Anthropos Editorial, 2010.

SAYAD, A. O que é um imigrante? In: Imigração ou os Paradoxos da Alteridade. São Paulo: Editora da Universidade de São Paulo, 1998. p. 45-72.

SEYFERTH, G. Imigração e (re)construção de identidades étnicas. In: Cruzando Fronteiras Disciplinares: um panorama dos estudos migratórios. PÓVOA NETO, H. e FERREIRA, A. P. (orgs.). Rio de Janeiro: Revan, 2005. pp. 17-34. 